\title{
A numerical approach on parametric sensitivity analysis for an aeronautic aluminium alloy turning process
}

\author{
H. Ijaz*, M. Zain-ul-abdein**, W. Saleem***, M. Asad****, T. Mabrouki***** \\ *Mechanical Engineering Department, University of Jeddah, Jeddah, Saudi Arabia, E-mail: hassan605@yahoo.com \\ **Mechanical Engineering Department, University of Jeddah, Jeddah, Saudi Arabia, E-mail: mzainulabdein@gmail.com \\ ***Mechanical Engineering Department, University of Jeddah, Jeddah, Saudi Arabia, E-mail: waqas95@yahoo.com \\ ****Mechanical Engineering Department, University of Management \& Technology, 54770 Lahore, Pakistan, \\ E-mail: masadakhtar@gmail.com \\ *****École Nationale d'Ingénieurs de Tunis (ENIT), Tunis, E-mail: tarek.mabrouki@enit.rnu.tn \\ cross $^{\text {ref }}$ http://dx.doi.org/10.5755/j01.mech.22.2.12825
}

\section{Introduction}

The usage of aluminum alloys like A2024-T351 as structural parts in aeronautic and avionic industry is very common these days due to its good strength to weight ratio properties. These types of materials undergo numerous dry cutting machining processes before taking final shape [1-2]. These materials experience severe cutting forces during the machining processes in the manufacturing industry that may affect the chip formation and work piece distortions [3]. In industry, different machining processes are used based on machinist models and empirical studies. High costs of experiments in terms of time, price and availability of expensive materials demand an alternative strategy in the form of finite element analysis to estimate them. Hence optimization of different machining parameters (like cutting speed, feed rate, tool geometry etc) with the help of finite element analysis attains a value of prime importance [4-5].

The cutting process in metals may be described as a crack like entity between the two surfaces i.e. chip and work piece. Two established theories, damage mechanics and fracture mechanics, may be employed to study the crack growth behavior in materials. Fracture mechanics theory established on the basis that a crack like entity already exists in material and it deals with the propagation of crack [6]. On the other hand damage mechanics theory not only predicts the propagation of crack but also simulate the process of crack initiation [7]. In the present work, Johson-Cook plasticity material model coupled with damage evolution law is adopted to simulate the crack growth behaviour between the two surfaces [8]. Johnson-Cook model provides description of metal material behavior by considering large strains, high strain-rates and temperature dependent viscoplasticity.

In the present study 2D finite element analysis of turning process of aluminum alloy A2024-T351 is performed to study the process of chip formation and different parameters affecting the aforementioned process using commercially available FE software, Abaqus/Explicit [9]. This particular finite element simulation study will help to understand the turning process of aluminum alloy and to optimize the machining parameters required for the turning process. The authenticity of finite element analysis is verified by comparing the simulation results with the available experimental data [10].

This article is organized as follows: in section 2, mathematical details of employed material model of Johnson-Cook are discussed. Section 3 contains the details of FE model and simulation results. Then a comprehensive parametric study is presented and discussed in section 4. Finally some concluding remarks are given in section 5 .

\section{Material model}

The Johnson-Cook material model is adopted in the present study for the cutting simulation and chip formation phenomenon. If $\bar{\sigma}$ is the equivalent plastic flow stress then following expression can be written [8]:

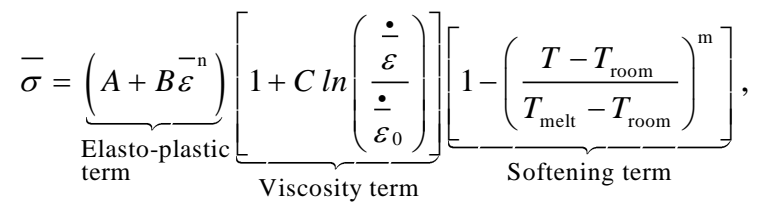

where $A, B$ and $n$ are material constants for strain hardening; $C$ is the material constant for strain hardening rate, $m$ is material constant for thermal softening effect, $T_{\text {room }}$ is the reference ambient temperature and $T_{m e l t}$ is the melting temperature of the material. Similarly in the above equation, $\bar{\varepsilon}$ is the equivalent plastic strain, $\dot{\bar{\varepsilon}}$ is the plastic strain rate, $\dot{\bar{\varepsilon}}_{0}$ $\stackrel{-}{\varepsilon}$

is the reference strain rate. If $\bar{\varepsilon}_{0 i}$ is the plastic strain at damage initiation then it can be expressed by following criteria [8]:

$$
\bar{\varepsilon}_{0 i}=\left[D_{1}+D_{2} \exp \left(D_{3} \frac{P}{\bar{\sigma}}\right)\right]\left[1+D_{4} \ln \left(\frac{\dot{\bar{\varepsilon}}}{\dot{\dot{\varepsilon}}}\right)\right] T_{J},
$$

where $T_{J}=\left[1+D_{5}\left(\frac{T-T_{\text {room }}}{T_{\text {melt }}-T_{\text {room }}}\right)\right] ; \quad D_{1}-D_{5}$ are damage constants that can be found from experiments and $P$ is the pressure stress [8]. During the analysis, the damage is initiated when a scalar damage parameter $\omega$ exceeds 1 and this parameter can be expressed as [11]:

$$
\omega=\frac{\sum \Delta \bar{\varepsilon}}{\bar{\varepsilon}_{0 i}}
$$

Based on Hillerborg's fracture energy proposal, the 
energy $G_{f}$ required to open a unit area of crack may be written as [12]:

$$
G_{f}=\int_{\bar{\varepsilon}_{0 i}}^{\bar{\varepsilon}_{f}} L \bar{\sigma}_{y} d \bar{\varepsilon}=\int_{0}^{\bar{u}_{f}} \bar{\sigma}_{y} d \bar{u} .
$$

In the above equation $L$ is the characteristic length of element and $\bar{u}_{f}$ is the equivalent plastic displacement at failure and can be computed by the following equation [13]:

$$
\bar{u}_{f}=\frac{2 G_{f}}{\sigma_{f}} .
$$

If $E$ is the modulus of elasticity of material and $v$ is the Poisson ratio then fracture energy $G_{f}$ for mode I and mode II crack growth can identified from experiments by the following relation [10]:

$$
\left(G_{f}\right)_{I, I I}=\left(\frac{1-v^{2}}{E}\right)\left(K_{C}^{2}\right)_{I, I I} .
$$

In the above equation $K_{I C}$ and $K_{I I C}$ are material constants for mode I and mode II crack growth respectively and termed as fracture toughness of the material. For A2024T351, the fracture toughness values are: $K_{I C}=26(\mathrm{MPa} \sqrt{m})$ and $K_{I I C}=37(\mathrm{MPa} \sqrt{m})$ [14]. A linear or exponential damage evolution law can be considered for degradation of material under applied force. If $D$ is damage variable, following two equations represent the linear and exponential type of damage evolution law respectively [14]:

$D=\frac{L \bar{\varepsilon}}{\bar{u}_{f}}=\frac{\bar{u}}{\bar{u}_{f}}$

$$
D=1-\exp \left(-\int_{0}^{\bar{u}} \frac{\bar{\sigma}}{G_{f}} d \bar{u}\right) .
$$

\section{Finite element analysis}

2D finite element analysis of turning process is performed using Abaqus/Explicit [9]. Johnson-Cook material model along with damage evolution law is available in Abaqus/Explicit. Four node quadrilateral continuum elements with plane strain assumption (CPE4RT) are used for coupled temperature-displacement analysis [15].

The geometry of the model and different boundary conditions are shown in Fig. 1. To optimize the contact conditions between the work piece and tool, the work piece component is divided into three partitions. Different partitions of work piece are: 1) chip 2) tool-tip passage zone and 3) work piece support. To facilitate the chip formation, the thickness of the tool-tip passage zone should be of the order of tool edge radius [16].These three partitions of work piece are joined together using the tie constraint option available in Abaqus/Explicit. During the cutting operation tool comes in contact with the work piece and chip, furthermore chip also makes self contact during the machining process. A coulomb friction model is employed for tool-chip-work piece interaction [17-18]. The finite element simulation requires the identification of different damage parameters [1921], The identified Johnson-Cook material parameters used for damage initiation and damage evolution for A2024T351 are given in Table 1 [14]. The different material properties of A2024-T351 are given in Table 2 [14].

In order to authenticate the simulation process, finite element analysis results will be compared with available experimental data on turning machining of A2024-T351. The experimental results of cutting forces against different cutting feeds and velocities are given in Table 3 [10].

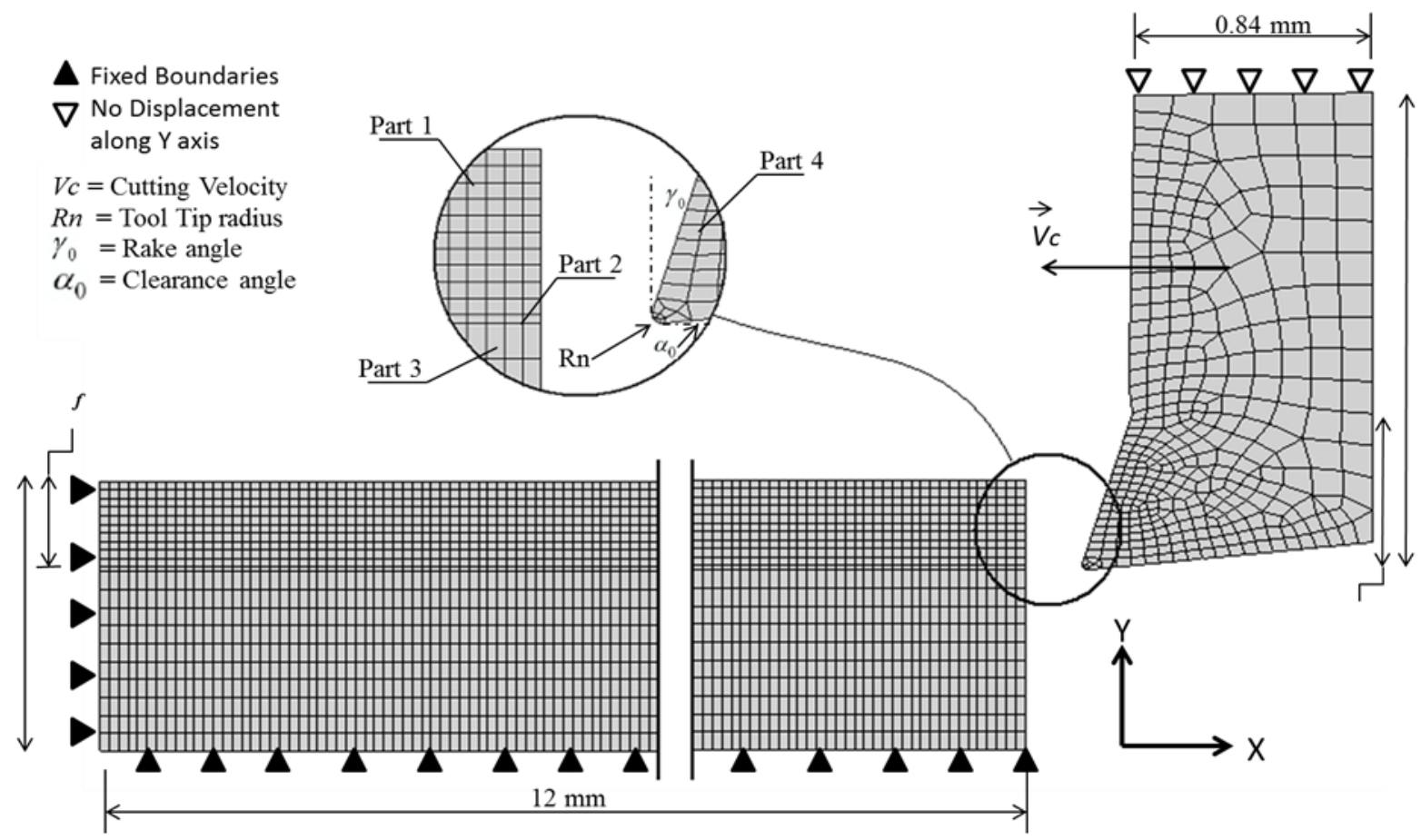

Fig. 1 Geometric model of work piece and tool 
In order to authenticate the simulation process, finite element analysis results will be compared with available experimental data on turning machining of A2024-T351. The experimental results of cutting forces against different cutting feeds and velocities are given in Table 3 [10].

In this section 2D finite element analysis of cutting process of A2024-T351 is performed for a feed rate $f=0.4 \mathrm{~mm}$ and friction coefficient $\mu=0.15$ against velocity $V c=800 \mathrm{~m} / \mathrm{min}$. Fig. 2 represents the reaction force $(F c)$ obtained from numerical analysis for cutting speed of $800 \mathrm{~m} / \mathrm{min}$. The average cutting force obtained from numerical results is $943.4 \mathrm{~N}$ and is in good agreement with experimental results. Since the deviation of numerical results from experimental results is of the order of $3.4 \%$ which shows the authenticity of simulation work. Fig. 3 shows the resultant Von misses stress profile during the chip formation process.

\section{Parameters affecting the cutting process}

In the previous section finite element analysis has been performed on turning simulation for A2024-T351 aluminium alloy and results are successfully compared with experimental results. After verifying the simulation results a comprehensive parametric sensitivity analysis considering different cutting parameters is performed in this section.

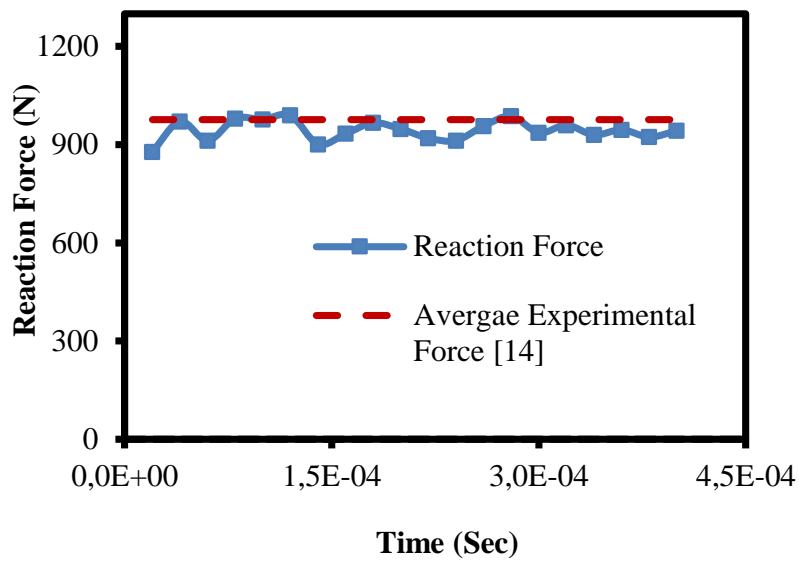

Fig. 2 Evolution of Reaction Force vs Time for cutting speed of $800 \mathrm{~m} / \mathrm{min}$

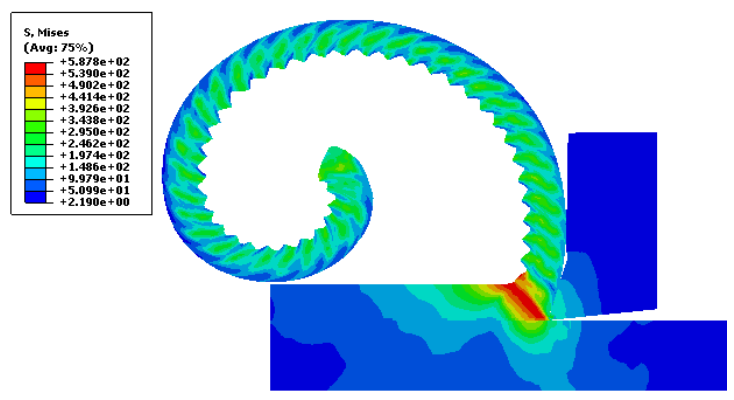

Fig. 3 Von misses stress profile at $800 \mathrm{~m} / \mathrm{min}$ cutting speed

Table 1

Johnson-Cook material parameters for A2024-T351 [14]

\begin{tabular}{|c|c|c|c|c|c|c|c|c|c|}
\hline$A, \mathrm{MPa}$ & $B, \mathrm{MPa}$ & $n$ & $C$ & $m$ & $D 1$ & $D 2$ & $D 3$ & $D 4$ & $D 5$ \\
\hline 352 & 440 & 0.42 & 0.0083 & 1 & 0.13 & 0.13 & -1.5 & 0.011 & 0 \\
\hline
\end{tabular}

Work piece and tool properties [14]

Table 2

\begin{tabular}{|c|c|c|}
\hline Physical parameter & Work piece (A2024-T351) & Tool (Tungsten Carbide) \\
\hline Density $\rho, \mathrm{Kg} / \mathrm{m}^{3}$ & 2700 & 11900 \\
\hline Elastic modulus $E, \mathrm{Gpa}$ & 73 & 0.22 \\
\hline Poisson ratio $v$ & 0.33 & 400 \\
\hline Specific heat $C_{p}, \mathrm{JKg}^{-1{ }^{\circ}} \mathrm{C}^{-1}$ & $C_{p}=0.557 \mathrm{~T}+877.6$ & 50 \\
\hline Thermal conductivity $\lambda, \mathrm{Wm}^{-1} \mathrm{C}^{-1}$ & $\begin{array}{r}25 \leq \mathrm{T} \leq 300: \lambda=0.247 \mathrm{~T}+114.4 \\
300 \leq \mathrm{T} \leq \mathrm{T}_{\text {melt }}: \lambda=-0.125 \mathrm{~T}+226.0\end{array}$ \\
\hline Expansion $\alpha, \mu \mathrm{mm}{ }^{-10} \mathrm{C}^{-1}$ & $\alpha+8.9 \times 10^{-3} \mathrm{~T}+22.2$ & $\mathrm{X}$ \\
\hline$T_{\text {melt }},{ }^{\circ} \mathrm{C}$ & 520 & $\mathrm{X}$ \\
\hline$T_{\text {room }},{ }^{\circ} \mathrm{C}$ & 25 & 25 \\
\hline
\end{tabular}

Experimental results [10]

Table 3

\begin{tabular}{|c|c|c|c|}
\hline \multicolumn{3}{|c|}{ Cutting force $F c, \mathrm{~N}$} \\
\hline \multirow{2}{*}{ Feed $f, \mathrm{~mm}$} & 200 & 400 & 800 \\
\cline { 2 - 4 } & $778 \mathrm{~N}$ & $769 \mathrm{~N}$ & $769 \mathrm{~N}$ \\
\hline 0.3 & $988 \mathrm{~N}$ & $978 \mathrm{~N}$ & $976 \mathrm{~N}$ \\
\hline 0.4 & &
\end{tabular}




\subsection{Effect of cutting speed}

The effect of different cutting speeds on the reaction force is studied in the present section. The values of feed rate $f=0.4 \mathrm{~mm}$ and friction coefficient $\mu=0.15$ are employed to study the effect of different values of cutting speed. Fig. 4 presents the variation of cutting force with cutting speed. Although from Fig. 4 a slight increasing trend is observed but there is not an appreciable difference in values of cutting force as the cutting speed increases from $200 \mathrm{~m} / \mathrm{min}$ to $800 \mathrm{~mm} / \mathrm{min}$. Similarly temperature profile at different velocities is shown in Fig. 5. From Fig. 5, one can note that by increasing the cutting speed, maximum temperature at the tool-chip interface also increases. In the present case, maximum temperature increases approximately from $231^{\circ} \mathrm{C}$ for $V c=200 \mathrm{~m} / \mathrm{min}$ to $336^{\circ} \mathrm{C}$ for $V c=800 \mathrm{~m} / \mathrm{min}$. Hence selection of cutting speed can be attributed to total time required to complete a job, machine capability \& accuracy, required surface finish and maximum affordable temperature of the work piece.

\subsection{Effect of feed rate}

The effect of feed rate $(f)$ on cutting force is considered in this section. Fig. 6 shows the results of cutting force $v s$ cutting speed for two different feed rate values i.e. $f=0.3 \& 0.4$ and $\mu=0.15$. The reaction forces obtained from numerical results are also in good agreement with experimental results, see Table 3 for comparison.

From Fig. 6, it is clear that reaction force decreases considerably as the feed rate $(f)$ decreases. Similarly, temperature profile at different feed rate $(f)$ is shown in Fig. 7. From Fig. 7, one can note that maximum nodal temperature increases with the increase in feed rate. Moreover the difference in rise in temperature at higher velocities is much higher in comparison of lower velocities. At $V c=200 \mathrm{~m} / \mathrm{min}$, the maximum temperature varies from $231^{\circ} \mathrm{C}$ to $237^{\circ} \mathrm{C}$ for $f=0.3$ and 0.4 respectively. But on the other hand as the cutting speed increases from 200 to $800 \mathrm{~m} / \mathrm{min}$, the maximum temperature varies from $301^{\circ} \mathrm{C}$ to $336{ }^{\circ} \mathrm{C}$ for $f=0.3$ and 0.4 respectively. Now selection of final cutting feed depends upon the total time to finish the work piece since small feed values will take more time to achieve final dimensions of finished parts. Moreover small feed values also carry the advantage of less cutting force and temperature values.

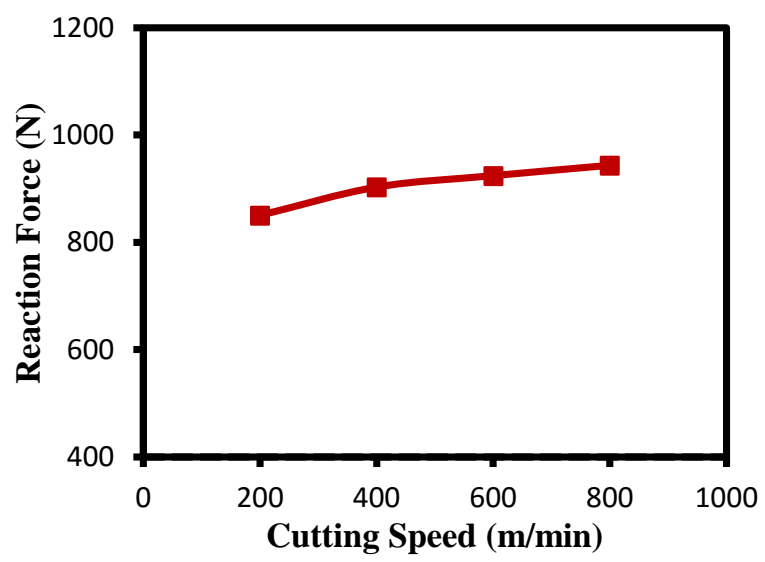

Fig. 4 Variation of cutting force $v s$ cutting speed
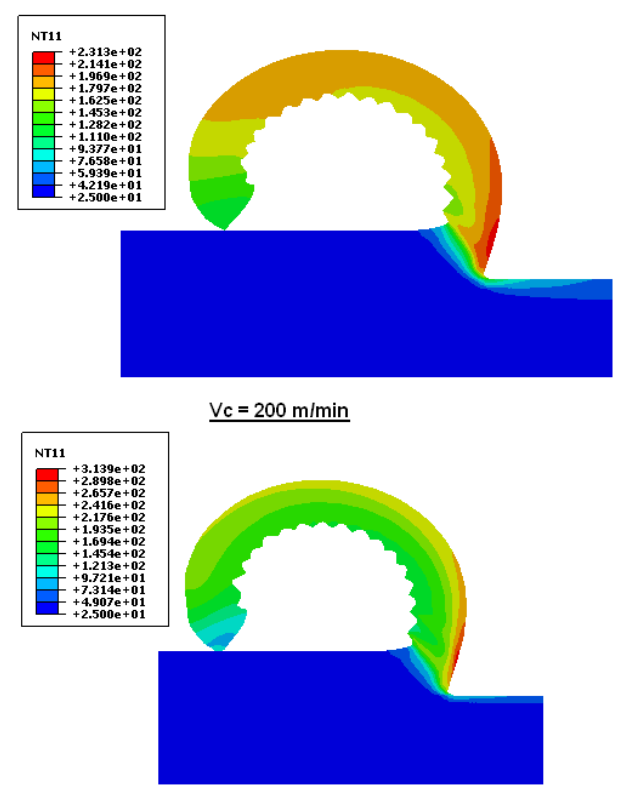

$\underline{\mathrm{V} c}=600 \mathrm{~m} / \mathrm{min}$

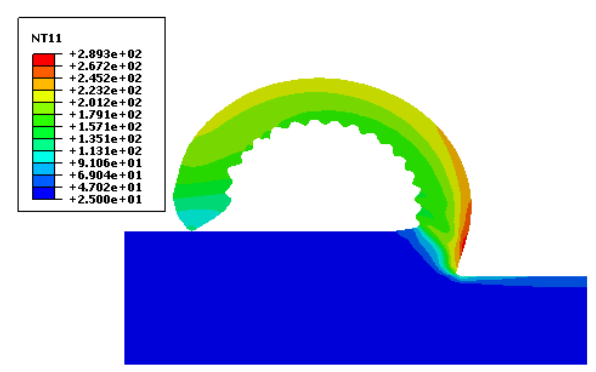

$\underline{V c}=400 \mathrm{~m} / \mathrm{min}$

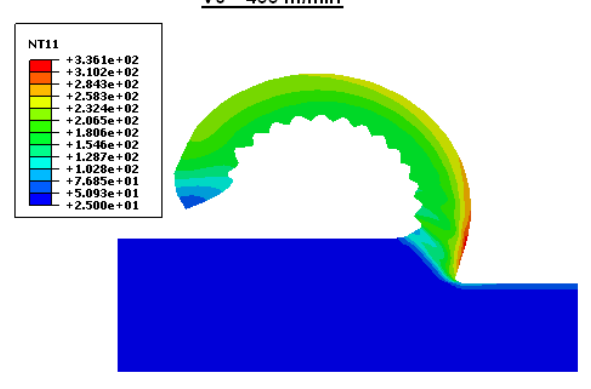

$\underline{\mathrm{Vc}}=800 \mathrm{~m} / \mathrm{min}$

Fig. 5 Temperature profile at different cutting speeds

\subsection{Effect of friction coefficient}

The friction coefficient between tool-chip interface also plays its role on the resultant cutting force values. The effect of friction coefficient $\mu$ on the reaction force is depicted in Fig. 8. In this figure, results for two feed rates, $f=0.3 \& 0.4$, are shown. The results show that the effect of friction coefficient on cutting reaction force is not that great as its value increased from 0.1 to 0.15 for both $f=0.3 \& 0.4$. On the other hand the friction coefficient value affects the temperature profile appreciably. From Fig. 9, one can observe that the maximum temperature increases from $258^{\circ} \mathrm{C}$ to $289^{\circ} \mathrm{C}$ for friction coefficient $\mu$ values of 0.1 and 0.15 respectively at cutting speed of $400 \mathrm{~m} / \mathrm{min}$. similarly this increase in temperature is from $293^{\circ} \mathrm{C}$ to $336^{\circ} \mathrm{C}$ for friction coefficient $\mu$ values of 0.1 and 0.15 respectively at cutting speed of $800 \mathrm{~m} / \mathrm{min}$. Moreover the friction coefficient value depends on the two cutting surfaces quality i.e. tool and work piece surfaces and direct control on this cutting parameter it is difficult to attain. 


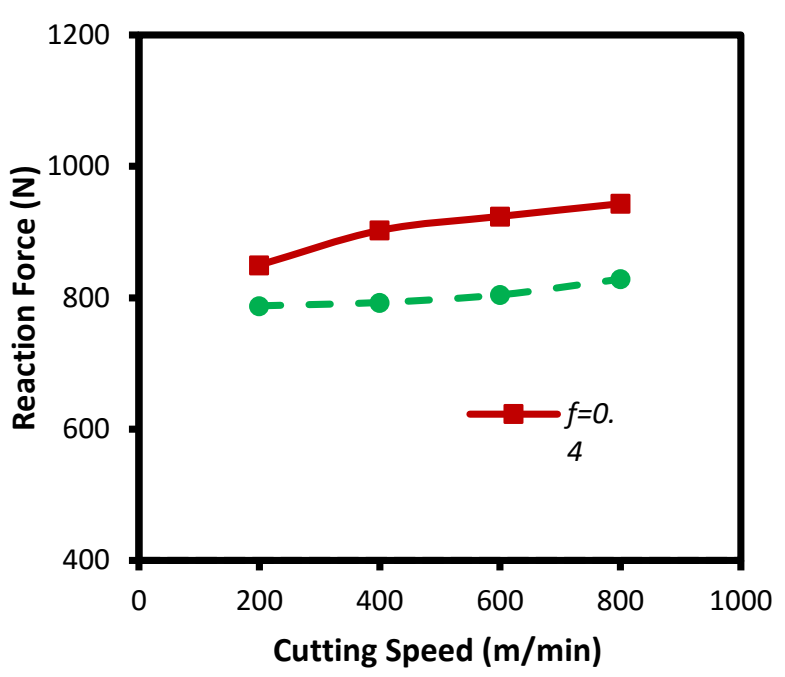

Fig. 6 Effect of feed $f$ on Reaction Force

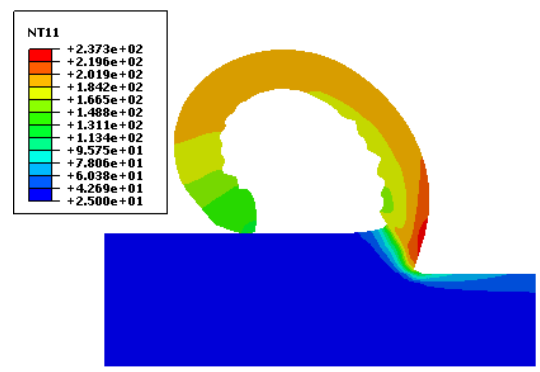

$V c=200 \mathrm{~m} / \mathrm{min}, f=0.3 \mathrm{~mm}$

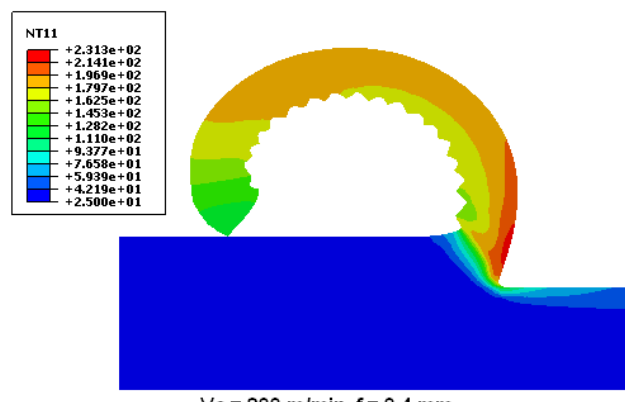

$V_{c}=200 \mathrm{~m} / \mathrm{min}, f=0.4 \mathrm{~mm}$

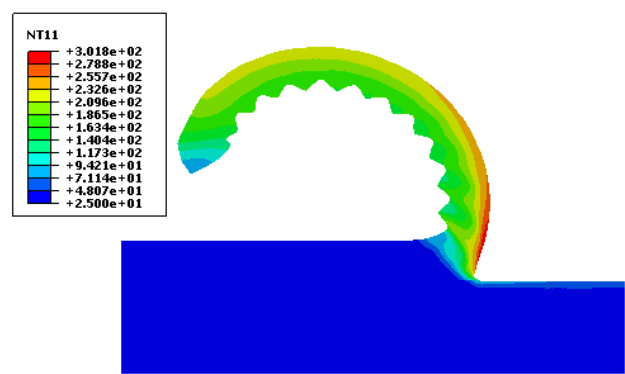

$V c=800 \mathrm{~m} / \mathrm{min}, f=0.3 \mathrm{~mm}$

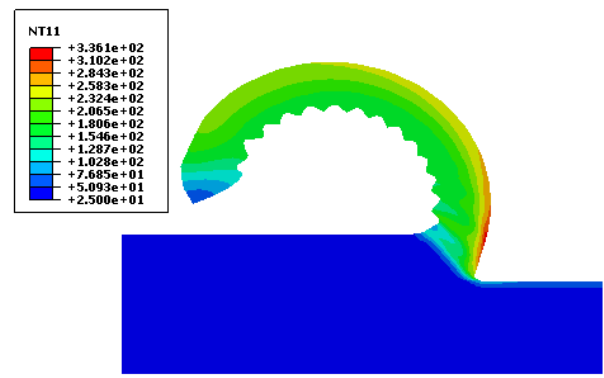

$\underline{V c}=800 \mathrm{~m} / \mathrm{min}, f=0.4 \mathrm{~mm}$

Fig. 7 Temperature profile at different feed $f$ values

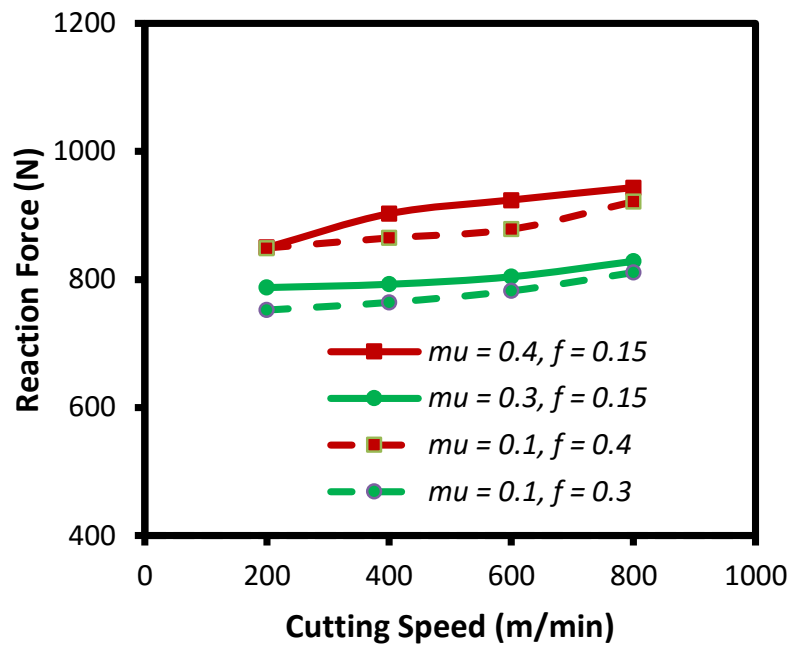

Fig. 8 Effect of Friction Coefficient $\mu(m u)$ on Reaction Force

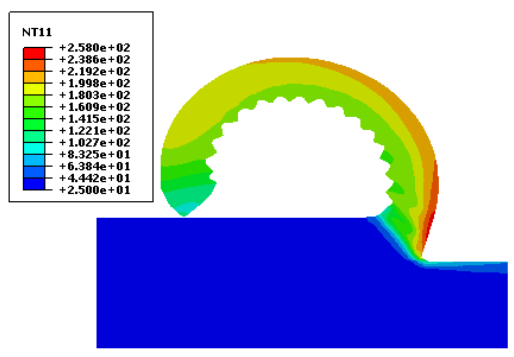

$\underline{V c}=400 \mathrm{~m} / \mathrm{min}, \mu=0.1$

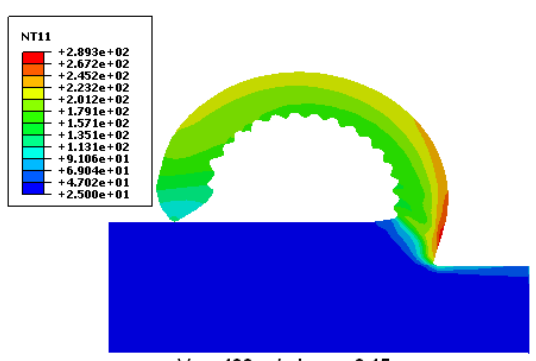

$\underline{V c}=400 \mathrm{~m} / \mathrm{min}, \mu=0.15$

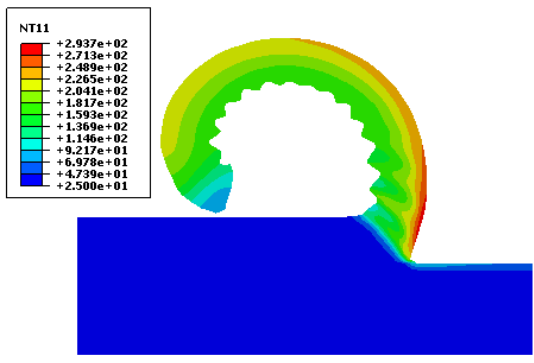

$\underline{V c}=800 \mathrm{~m} / \mathrm{min}, \mu=0.1$

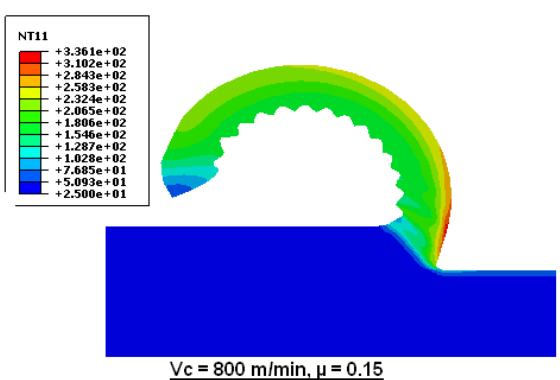

Fig. 9 Temperature profile at different Friction coefficient $\mu$ values 


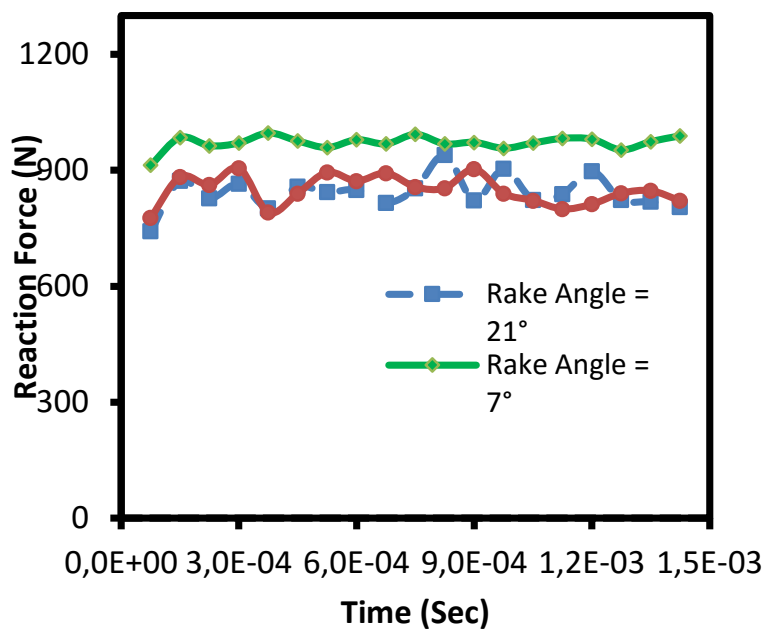

Fig. 10 Evolution of Reaction Force for different rake angles at cutting speed of $200 \mathrm{~m} / \mathrm{min}$
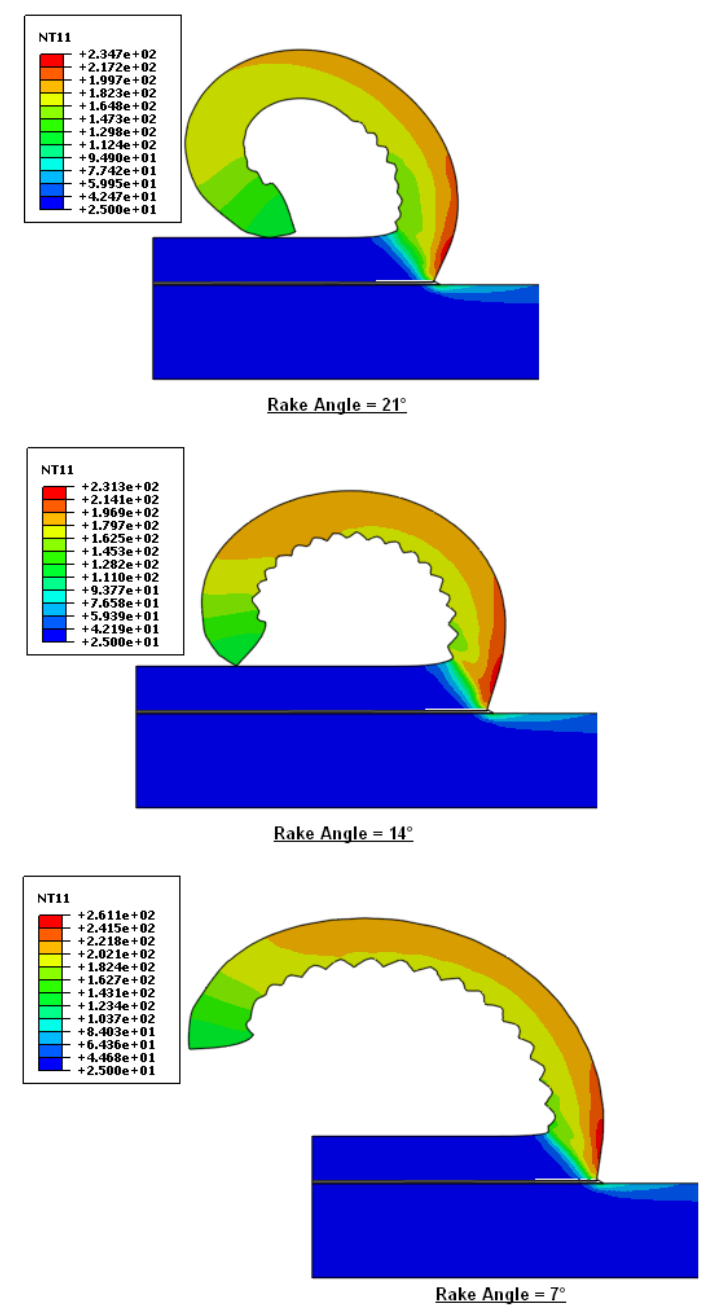

Fig. 11 Temperature profile for different rake angles at cutting speed of $200 \mathrm{~m} / \mathrm{min}$

\section{Conclusions}

In this article a comprehensive study is conducted on different parameters that influence the turning process of aluminium alloy using the finite element analysis. The authenticity of finite element work is verified by comparing the results with available experimental data. The effect of four different parameters like cutting speed, feed rate, friction coefficient and rake angle on resultant reaction force is studied. The effect of cutting speed and friction coefficient on the reaction force is not much significant but they appreciably affect the maximum temperature at the tool-chip interface. On the other hand both feed rate and rake angle have strong influence not only on cutting reaction force but also on maximum tool-chip interface temperature. From the conducted study one can say that these parameters may influence the total time required to complete the job and the net resultant force experienced by the tool and work piece. Hence the selection of good parameters for a particular turning process of aluminium alloy may depend on the required total time to finish the job and net resultant forces that work piece and tool can withstand during turning operation. Finally one can also conclude that finite element analysis may replace the critical experimental work and help to save precious time and money. In the present work, a 2D finite element analysis is performed and good numerical results that are comparable with the experimental results are obtained. But the same effort will be made in future on 3D finite element analysis for better and real time analysis of turning process in metals.

\section{References}

1. Nicolaou, P.; Thurston, D.L.; Carnahan, J.V. 2002. Machining quality and cost estimation and tradeoffs, Journal of Manufacturing Science and Engineering 124: 840-851. http://dx.doi.org/10.1115/1.1511169.

2. Sreejith, P.S.; Ngoi, B.K.A. 2000. Dry machining: machining of the future, Journal of Materials Processing Technology 101: 287-291. http://dx.doi.org/10.1016/S0924-0136(00)00445-3.

3. List, G.; Nouari, M.; Géhin, D.; Gomez, S.; Manaud, J.P.; Le Petitcorps, Y.; Girot, F. 2005. Wear behaviour of cemented carbide tools in dry machining of aluminium alloy, Wear 259: 1177-1189. http://dx.doi.org/10.1016/j.wear.2005.02.056.

4. Fang, N.; Wu, Q. 2005. The effects of chamfered and honed tool edge geometry in machining of three aluminium alloys, International Journal of Machine tools \& Manufacturing 45: 1178-1187. http://dx.doi.org/10.1016/j.ijmachtools.2004.12.003.

5. Karpat, Y.; Özel, T. 2006. Predictive analytical and thermal modeling of orthogonal cutting process-part I: predictions of tool forces, stresses, and temperature distributions, Journal of Manufacturing Science and Engineering 128: 435-444.

http://dx.doi.org/10.1115/1.2162590.

6. Pommier, S.; Gravouil, A.; Combescure, A.; Moës, N. 2011. Extended Finite Element Method for Crack Propagation, 1st Edition, John Wiley \& Sons Inc., Hoboken, NJ USA, 256 p.

7. Ijaz, H.; Asad, M.; Gornet, L; Alam, S.Y. 2014. Prediction of delamination crack growth in carbon/fiber epoxy composite laminates using non-local interface damage model, Mechanics \& Industry 15(4): 293-300. http://dx.doi.org/10.1051/meca/2014030.

8. Johnson, G.R.; Cook, W.H. 1985. Fracture characteristics of three metals subjected to various strains, strain rates, temperatures and pressures, Engineering Fracture Mechanics 21: 31-48. 
http://dx.doi.org/10.1016/0013-7944(85)90052-9.

9. ABAQUS ${ } /$ EXPLICIT. 2009. Theory and user manuals, Version 6.9.

10. Asad, M. 2010. Elaboration of concepts and methodologies to study peripherical down-cut milling process from macro-to-micro scales, PhD Thesis, INSA-Lyon, France.

11. Han, Z.Y.; Huang, X.G.; Cao, Y.G.; Xu, J.Q. 2014. A non linear cumulative evolution model for corrosion fatigue damage, Journal of Zhejiang University Science A 15(6): 447-453.

http://dx.doi.org/10.1631/jzus.A1300362.

12. Hillerborg, A.; Modeer, M.; Petersson, P.E. 1976. Analysis of crack formation and crack growth in concrete by means of fracture mechanics and finite elements, Cement \& Concrete Research 6(6): 773-781. http://dx.doi.org/10.1016/0008-8846(76)90007-7.

13. Shi, J.; Liu, C.R. 2006. On predicting chip morphology and phase transformation in hard machining, The International Journal of Advanced Manufacturing Technology 27(7-8): 645-654. http://dx.doi.org/10.1007/s00170-004-2242-0.

14. Asad, M.; Mabrouki, T.; Girardin, F.; Zhang, Y.; Rigal, J.-F. 2011. Towards a physical comprehension of material strengthening factors during macro to microscale milling, Mechanika 17(1): 97-104. http://dx.doi.org/10.5755/j01.mech.17.1.210.

15. Bäker, M. 2005. Finite element investigation of the flow stress dependence of chip formation, Journal of Materials Processing Technology 167(1): 1-13. http://dx.doi.org/10.1016/j.jmatprotec.2004.09.076.

16. Subbiah, S; Melkote, S.N. 2008. Effect of finite edge radius on ductile fracture ahead of the cutting tool edge in micro-cutting of Al2024-T3, Materials Science and Engineering: A 474(1-2): 283-300. http://dx.doi.org/10.1016/j.msea.2007.04.116.

17. Zhang, X.; Wu, S.; Wang, H.; Liu, C.R. 2011. Predicting the effects of cutting parameters and tool geometry on hard turning process using finite element method, Journal of Manufacturing Science and Engineering 133(4): 041010/1-041010/13. http://dx.doi.org/10.1115/1.4004611.

18. Li, K.; Gao, X.L.; Sutherland, J.W. 2002. Finite element simulation of the orthogonal metal cutting process for qualitative understanding of the effects of crater wear on the chip formation process, Journal of Materials Processing Technology 127(3): 309-324. http://dx.doi.org/10.1016/S0924-0136(02)00281-9.
19. Teng, X.; Wierzbicki, T. 2006. Evaluation of six fracture models in high velocity Perforation, Engineering Fracture Mechanics 73(12): 1653-1678.

http://dx.doi.org/10.1016/j.engfracmech.2006.01.009.

20. Ozel, T.; Karpat, Y. 2007. Identification of constitutive material parameters for high strain rate cutting conditions using evolutionary computational algorithms, Materials and Manufacturing Processes 22(7): 659-667. http://dx.doi.org/10.1080/10426910701323631.

21. Baker, M. 2015. A new method to determine material parameters from machining simulations using inverse identification, Procedia CIRP 31: 399-404. http://dx.doi.org/10.1016/j.procir.2015.04.090.

H. Ijaz, M. Zain-ul-abdein, W. Saleem, M. Asad, T. Mabrouki

\section{A NUMERICAL APPROACH ON PARAMETRIC SENSITIVITY ANALYSIS FOR AN AERONAUTIC ALUMINIUM ALLOY TURNING PROCESS}

S u m m a r y

The understanding of physical parameters of machining processes of aerospace grade aluminium alloy is always of prime importance. The main concern is always to understand the chip formation process and the resultant cutting force experienced by the tool due to different parameters like cutting speeds, feed rate, friction coefficient and tool rake angle etc. The finite element analysis has replaced many expensive and time consuming physical machining processes. In the present work, an extensive study of different parameters affecting the turning process of aluminium alloy (A2024-T351) is performed using 2D finite element analysis. The Johnson-Cook ductile material model based on coupled plasticity and damage evolution is employed to simulate the cutting process. The authenticity of the performed simulation work is verified by comparing the simulation results with available experimental data on machining of aluminium alloy (A2024-T351).

Keywords: Finite element analysis, Johnson-Cook material model, Damage evolution, A2024-T351 al alloy.

Received July 31, 2015 Accepted March 15, 2016 